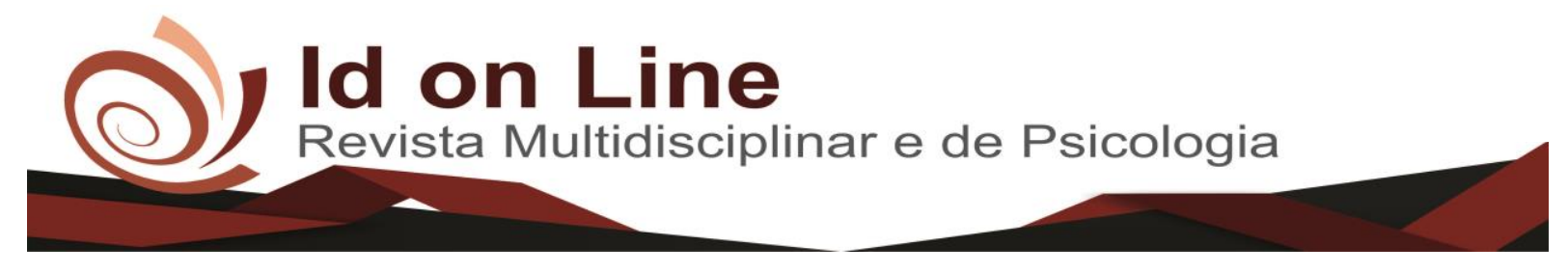

DOI: 10.14295/idonline.v14i49.2342

Relato de Caso

\title{
Hemangioendotelioma Epitelioide Hepático: Relato de Caso de uma rara Neoplasia
}

Ana Maria Rodrigues Lima Medeiros ${ }^{1}$; Heliofábia Gomes Freitas ${ }^{2}$

Resumo: O hemangioendotelioma epitelioide é um raro tumor vascular, composto por um estroma fibroso hialinizado e células epitelioides. É marcado por um crescimento lento, que pode levar à insuficiência hepática e consequentemente à morte. Em alguns casos porém, a regressão espontânea também pode ser observada. Relata-se o caso de um paciente de 26 anos, sexo masculino, com tumor diagnosticado após dor abdominal de forte intensidade. O paciente foi submetido à videolaparoscopia, com anátomopatológico e imunohistoquímica compatíveis com hemangioendotelioma epitelioide hepático.

Palavras chave: hemangioendotelioma; hepático; tumor.

\section{Hepatic Epithelioid Hemangioendothelioma: Case Report of a rare neoplasm}

Abstract: Epithelioid hemangioendothelioma is a rare vascular tumor, composed of hyalinized fibrous stroma and epithelioid cells, It is marked by slow growth, which can lead to liver failure and consequently to death. However, in some cases, spontaneous regression can also be observed. The case of a 26-year-old male patient with a tumor diagnosed after sever abdominal pain. The patient underwent videolaparoscopy, withanatomopathological and immunohistochemistry compatible with epithelioid hemangioendothelioma of the liver.

Keywords: hemangioendothalioma; hepatic; tumor.

\section{Introdução}

O hemangioendotelioma epitelioide hepático (HEH) é uma entidade neoplásica vascular rara de etiologia ainda desconhecida ${ }^{1}$, pode mimetizar tumores vasculares como o angiossarcoma, no entanto a preservação da estrutura acinar hepática, a esclerose densa, a hialinização e a calcificação dos nódulos tumorais do HEH não são observados no angiossarcoma.

\footnotetext{
${ }^{1}$ Médica Residente do programa de Clínica médica do Hospital UDI em São Luís-MA; anamariaamed@ yahoo.com.br; ${ }^{2}$ Médica oncologista Clínica do Hospital do Câncer do Maranhão em São Luis-MA; heliofabia.freitas@ gmail.com.
} 
Outros diagnósticos diferenciais são feitos com hepatocarcinoma fibrolamelar, colangiocarcinoma, tumores mistos, sarcoma e de carcinomas metastáticos ${ }^{2}$. Relatamos um caso de um paciente, masculino, adulto jovem, com diagnóstico de hemangioendotelioma epitelioide hepático.

\section{Descrição do caso}

Paciente do sexo masculino com 26 anos de idade, residente em São Luis-MA, barbeiro, sem doenças prévias, com queixa de dor abdominal intensa associada a epigastralgia há 5 meses, nega febre, diarreia, perda ponderal. Ao exame físico apresentava dor à palpação abdominal profunda em quadrante superior direito sem sinais de irritação peritoneal.

Realizou Ultrassonografia de abdome superior que revelou em topografia hepática lesão expansiva heterogênea, com focos hiperecoicos medindo cerca de 8,9x7,6x6,3 cm localizada no segmento VI e VII. A Tomografia computadorizada (TC) de abdome demonstrou no fígado formações teciduais heterogêneas a maior no situada no lobo direito, medindo cerca de 7,9x9,4 $\mathrm{cm}$.

O exame histopatológico, após realizar videolaparoscopia para biópsia hepática, revelou deposição de substância hialina em parênquima hepático, proliferação ductuolar periférica e recomendou estudo imunohistoquímico.

A imunohistoquímica evidenciou hemangioendotelioma epitelioide com positividade para ERG (ETS Family) e CAMTA 1. O paciente evolui em seguimento com oncologia clínica que solicitou exames de imagem para estadiamento, avaliação de tratamento quimioterápico e discussão do caso com grupo sarcoma e posterior avaliação da cirurgia oncológica.

\section{Discussão}

O HEH é um tumor vascular raro descrito pela primeira vez em 1982 por Weiss e Enzinger ${ }^{3}$. O acometimento do tecido hepático pode ser nodular ou difuso. O padrão nodular é marcado pela presença de múltiplas lesões de variados tamanhos, enquanto o difuso decorre da coalescência dos nódulos, gerando uma lesão periférica lobar única infiltrativa ${ }^{4}$. Clinicamente os pacientes são oligossintomáticos ou mesmo assintomáticos. Sintomas como icterícia, febre e sangramento digestivo (devido à hipertensão portal) podem estar presentes, porém são

378 Id on Line Rev. Mult. Psic. V.14, N. 49 p. 377-380, Fevereiro/2020 - ISSN 1981-1179 
incomuns ${ }^{5}$. Achados em exames como Ultrassonografia e Tomografia computadorizada incluem hepatoesplenomegalia, sinais de hipertensão portal e mais tardiamente compressão tumoral ${ }^{6}$. Não é fácil fazer recomendações sobre a terapia necessária ao tratamento do HEH pelo fato da história natural da doença ser muito heterogênea. No entanto a cirurgia radical continua sendo a mais indicada ${ }^{7}$.

\section{Conclusão}

Com base no limitado número de casos relatados, o hemangioendotelioma epitelioide hepático é um tumor de agressividade baixa/intermediária, com apresentação clínica e prognóstico variados, sendo importante o conhecimento desta patologia na prática clínica para reconhecimento do mesmo.

\section{Referências:}

1. Makhlouf HR, Ishak KG, Goodman ZD. Epithelioid hemangioendothelioma of the liver. A clinicopathologic study of 137 cases. Cancer. 1999;85(3):562-80.

2. Dos Santos, G., Collazo, C., \& Maciel, G. (2011). Hemangioendotelioma epitelioide hepático diseminado: a propósito de un caso. Revista Médica del Uruguay, 27(2), 94-97.

3. Lyburn, I. D., Torreggiani, W. C., Harris, A. C., Zwirewich, C. V., Buckley, A. R., Davis, J. E., ... Ho, S. G. F. (2003). Hepatic Epithelioid Hemangioendothelioma: Sonographic, CT, and MR Imaging Appearances. American Journal of Roentgenology, 180(5), 13591364. doi:10.2214/ajr.180.5.1801359.

4. Torres LR, Timbó LS, Ribeiro CMF, Galvão Filho MM, Verrastro CGY, D’Ippolito G. Hemangioendotelioma hepático multifocal e metastático: relato de caso e revisão da literatura. Radiol Bras. 2014 Mai/Jun;47(3):194-196.

5. Santos CER, Correia MM, Pereira RS, et al. Hemangioendotelioma epitelióide hepático: relato de caso com tratamento multimodal. Rev Bras Cancerol. 2007;53:217-22.

6. Sempoux, C., Van Beers, B. E., Danse, E., Horsmans, Y., Rahier, J., Roggen, F., ... Ciccarelli, O. (2004). Hepatic haemangioendothelioma in adults: excellent outcome following liver transplantation. Transplant International, 17(4), 202207. doi:10.1007/s00147-004-0697-4. 
7. Ishak, K. G., Sesterhenn, I. A., Goodman, M. Z. D., Rabin, L., \& Stromeyer, F. W. (1984). Epithelioid hemangioendothelioma of the liver: A clinicopathologic and follow-up study of 32 cases. Human Pathology, 15(9), 839-852. doi:10.1016/s0046-8177(84)80145-8

\section{Como citar este artigo (Formato ABNT):}

MEDEIROS, Ana Maria Rodrigues Lima; FREITAS, Heliofábia Gomes. Hemangioendotelioma Epitelioide Hepático: Relato de Caso de uma rara Neoplasia. Id on Line Rev.Mult. Psic., Fevereiro/2020, vol.14, n.49, p. 377-380. ISSN: 1981-1179.

Recebido: 03/02/2020;

Aceito: 06/02/220. 